\title{
LA MIRADA SOBRE EL OTRO. \\ UNA APROXIMACIÓN ACERCA DE LA PERCEPCIÓN DE ALUMNOS ARGENTINOS SOBRE LA POBLACIÓN CHILENA EN NEUQUÉN
}

\section{Ángel CERUTTI - Cecilia GONZÁLEZ ${ }^{1}$}

\begin{abstract}
Resumen
.Este articulo se inscribe en el marco del proyecto de investigación "La mirada xenófoba. Migrantes chilenos en Neuquén. Discriminación y prejuicio. Una perspectiva actual", y en él se realiza un análisis de las posturas de alumnos del turno noche de una escuela secundaria respecto a la población chilena en el Neuquén; estos alumnos pertenecen a los sectores populares y concurren al CPEN $\mathrm{N}^{\circ} 8$ de la localidad de Plottier, provincia del Neuquén, lugar donde se llevo a cabo el trabajo de campo.

Las respuestas obtenidas reflejan actitudes de prejuicio antichileno. Se sostiene que el prejuicio se encuentra potenciado por la necesidad de "diferenciarse" de los que por algún rasgo pueden ser considerados "inferiores", frente a la creciente pauperización de los sectores medios y populares y que las limitadas políticas sociales y el desempleo contribuyen a retroalimentarlo.

Palabras clave: Migrantes- Norpatagonia- Prejuicio-Discriminación- Xenofobia
\end{abstract}

\begin{abstract}
This article is part of the framework of the research project "The look xenophobic. Chilean migrants in Neuquén. Discrimination and prejudice. A current perspective", and presents an analysis of a group of night-shift secondary school students' views on Chileneans in Neuquen. Their answers reflect an attitude of prejudice against Chileans. Prejudice is enhanced by the need to establish differences from those who, due to some traits, can be considered "inferior" in the context of the growing impoverishment of middle-class and popular sectors and the fact that the limited social policies and unemployment contribute to kindle it.
\end{abstract}

Keywords: Migrants- Norpatagonia- Prejudice- Discrimination- Xenophobia

\section{Résumé}

Ce document fait partie du projet de recherche «L'aspect xénophobe. Migrants chiliens à Neuquèn. La discrimination et les préjugés. Un point de vue actuel », et il est une analyse de la situation des étudiants de nuit de l'école secondaire par rapport à la population du Chili dans la province de Neuquèn; ces élèves appartiennent à des secteurs populaires et en contribuant à la CPEN N 8 dans la ville de Plottier, la province de Neuquèn, où ils ont mené le travail de terrain.

\footnotetext{
${ }^{1}$ Universidad Nacional del Comahue

Fecha de recepción del artículo: Septiembre 2010

Fecha de evaluación: Octubre 2010
} 
Les réponses reflètent les attitudes des anti-préjugés chiliens. Il est soutenu que le préjudice est alimenté par la nécessité de "distinguer" d'un trait de caractère qui peuvent être considérées comme "inférieures", l'adresse de la paupérisation croissante de la politique de moyennes et populaires les secteurs et sociale limitée et le chômage contribuent à la rétroaction. Mots-clés : Migrants- Norpatagonia- Partialité- La discrimination- La xénophobie

\section{Introducción}

Desde hace tiempo, la actual provincia del Neuquén -como las demás jurisdicciones que integran la Patagonia argentina- ha sido escenario de una fluida migración protagonizada por personas de escasos recursos provenientes del sur de Chile, con el propósito de mejorar sus condiciones de vida.

Coincidiendo con el establecimiento de esta población trascordillerana en la región, especialmente a partir de la última etapa del siglo XIX, se elaboran por parte de los sectores ilustrados -militares, periodistas, maestros, comerciantes y funcionarios públicos- prejuicios xenófobos, quienes de diversas formas entienden afectados sus intereses por esta presencia extranjera (Cerutti -Lvovich, 1994: 229-230).

En la actualidad, el prejuicio antichileno en el Neuquén, lejos de desaparecer o atenuarse, se ha mantenido constante y se ha difundido entre los sectores populares de la provincia. Esto es así más allá de que la inmigración chilena es menor, ya que las condiciones que imperaban en otro Este prejuicio social combina imágenes acerca de los sujetos sociales que se quiere estigmatizar. Así el inmigrante chileno será visto por una importante porción de la sociedad neuquina como "el otro" peligroso al convertirse en un "invasor pasivo" del territorio, como "saqueador" de los puestos de trabajo de la población nativa, como "aprovechador" de los servicios de salud, educación y vivienda que brinda la provincia, como "responsable" de la inseguridad existente (Mármora, 1997: 34-35).

Estos antecedentes resultan imprescindibles para abordar el objeto de este trabajo, que es el análisis de las opiniones que tienen un grupo de alumnos de nacionalidad argentina sobre la población chilena en el Neuquén.

Se llega a esta indagación a partir de la observación del lenguaje y actitudes cotidianas en el ámbito escolar, que implican prejuicio negativo, y actitudes discriminatorias, hacia personas que integran grupos que son estigmatizados por la población: chileno, boliviano, indio; pero la utilización más frecuente es la de "chileno", como si la palabra en sí, entrañara un insulto.

El hecho de que, estas actitudes de los alumnos, en la mayoría de las ocasiones, no llame la atención de los adultos responsables en la institución, y por lo tanto no implique ningún tipo de reflexión o sanción al respecto, fue también objeto de análisis. Esta situación, se da por compartir un imaginario social que acepta en términos generales, estas apreciaciones. Imaginarios que no son sólo monopolio de portadores de un pensamiento patriotero, sino que abarcan un universo social más amplio, donde sectores que se caracterizan por posiciones progresistas y contestatarias, también son partícipes del prejuicio antichileno.

Si bien se analizará específicamente el turno nocturno, se formuló el mismo cuestionario a alumnos que concurren al turno diurno, y si bien los adolescentes utilizan verbalmente estas expresiones con más frecuencia, al momento de reflejarlo por escrito, no aparece de manera tan descarnada el prejuicio como en el grupo que cursa a la noche.

Los alumnos del turno noche, no utilizan de manera frecuente la expresión "chileno", cuando quieren referirse negativamente a una persona, pero la estigmatización existe, y al momento de ponerlo por escrito buscan un fundamento para sus posturas, y generalmente tiene que ver con el acceso a los recursos sociales.

El planteo del presente trabajo se centra en el análisis del prejuicio reflejado en las posturas de los alumnos del turno noche, quienes pertenecen a los sectores populares; se sostiene que las limitadas políticas sociales y el desempleo contribuyen a retroalimentarlo; pero además, se encuentra potenciado por la necesidad de diferenciarse de los que por algún rasgo pueden ser considerados inferiores dentro de una creciente pauperización de los sectores medios y populares, ya que las condiciones de vida no le permiten esta diferenciación; desde las visiones 
consideradas, se juega la fantasía de que "desapareciendo" la población chilena, la situación socioeconómica cambiaría totalmente.

\section{Metodología de trabajo}

La modalidad utilizada para elaborar este trabajo está sustentada en el método etnográfico al que se puede definir como "el modo de investigación en el cual el investigador observa a sus sujetos en las condiciones de vida ambientales más usuales y no en las condiciones de laboratorio. En antropología cultural se usa a menudo como complemento la entrevista" (G. y A. Theordesen, 1978: 182)

Se llevaron a cabo entrevistas focalizadas estructuradas y no estructuradas, a personas relacionadas con los alumnos, y por supuesto a los alumnos, que voluntariamente se prestaron a esta indagación. A modo de complemento, se recurrió a la implementación de un cuestionario que se llevó a cabo durante los meses de octubre y noviembre en el aula.

\section{Identificación de alumnos}

Los sujetos sociales con los cuales se llevó a cabo la presente indagación presentan las siguientes características o señas de identificación:

a) Todos son alumnas y alumnos del segundo año -turno nocturno- del C.P.E.M. $\mathrm{N}^{\mathrm{o}} 8$ sito en la localidad de Plottier, a pocos kilómetros de la ciudad de Neuquén. El establecimiento educativo está ubicado en el radio céntrico de dicha población.

b) Los alumnos en cuestión pertenecen a sectores populares. Algunos de ellos se encuentran desocupados y sobreviven gracias a la ayuda social; otros, los más, realizan trabajos con cierto grado de precariedad (empleados en estaciones de servicios, en supermercados, en empleos domésticos, en comercio y algunos son peones de chacra u obreros de construcción).

c) El capital cultural con que cuentan los alumnos en cuestión, es extremadamente pobre. Es decir se está hablando de personas que están en constante lucha por

La indagación sobrevivir y conservar "cueste lo que cueste" sus empleos.

Se trabajan tres ejes los cuales pueden traducirse de la siguiente forma:

- ¿En qué aspectos modifica la forma de vida de los argentinos, la presencia de personas de nacionalidad chilena en la región?

- Si usted tuviera la posibilidad de decidir; ¿qué acción realizaría con la población chilena que habita la región?

- ¿Qué opina acerca de las fiestas patrias chilenas celebradas en Neuquén?

El análisis de estos testimonios, significa una primera aproximación a lo expresado por los jóvenes en el trabajo. Debido a la recurrencia de las expresiones que se vertieron en el mismo, se ha creído conveniente agruparlas en diferentes aspectos

\section{El trabajo y los servicios sociales}

La situación actual está signada por la crisis del estado de bienestar y la aparición de políticas neoliberales, lo cual significa la precarización casi total de la vida de los sectores populares: una seguridad social prácticamente inexistente, y sumado a ello, la desocupación y la subocupación en general, que tienden a que se conviertan en ex -hombres, grandes conjuntos sociales.

No se ahondará en este trabajo en esta descripción -por otra parte, ya conocida por todos-, ya que el interés se centra en analizar la vinculación de esta situación con expresiones que reflejan prejuicios hacia un grupo en particular, en este caso los chilenos. Tampoco se pretende afirmar que sean el único grupo estigmatizado, al producirse un traslado de la situaciones sociales conflictivas a conflictos étnicos, sino que por las particularidades de Neuquen, la presencia del chileno ha generado el surgimiento de prejuicios muy específicos de amplios sectores de la sociedad nacional. 
En el trabajo de campo, las opiniones vertidas por los alumnos hacen principal hincapié en el problema laboral, es decir, en la desocupación y trabajo en negro que padecen grandes conjuntos sociales, inclusive algunos de nuestros entrevistados. Expresiones tales como: "vienen, hacen sus casas y se llenan de plata a costa nuestra"; "si no estuvieran los chilenos, tendríamos más oportunidades de trabajo y de vivienda"; "les quitan trabajo a los argentinos, les dan casa y a muchos nacionales no"; "ellos reciben más beneficios que los de acá"; "son más beneficiados que los argentinos, tienen trabajo, vivienda, trabajan por poco"; fueron las más comunes entre las respuestas obtenidas. Cabe aclarar que la pregunta era de carácter general, y no hacía referencia a este aspecto en particular. La observación realizada respecto al mundo laboral, surge específicamente de las respuestas.

En nuestras charlas informarles con los alumnos, se pudo visualizar que ellos no desvinculan esta crisis generalizada, de las políticas públicas ejecutadas por el estado, sin embargo en los hechos concretos la mirada de culpabilidad se detiene casi únicamente en la población chilena; esto es así, aún cuando se analiza la situación de pauperización del salario, o se busca "justificar" la presencia de los chilenos; frases tales como: "trabajan por nada" o "realizan el trabajo que no quieren hacer los argentinos", implican adjudicarles responsabilidad respecto a los magros salarios y la precarización laboral.

La cantidad de población que en la actualidad debe pelear por trabajo y acceso a los recursos, en una provincia como Neuquén, en la que el estado siguió cumpliendo un papel central en la asistencia social, aún después de la crisis del estado de bienestar, en la que el recuerdo, fundamentalmente transmitido por sus mayores, de que hubo una época en que había trabajo para todos, y que los salarios permitían el acceso a consumos básicos, hace suponer a los alumnos de que muchas personas, originarias del sur de Chile y del norte del país, vinieron a quedarse con los trabajos y viviendas, que les corresponderían a los neuquinos. Obviamente quienes quedan mal parados en esta situación, son los chilenos, ya que los del norte, al menos son argentinos.

Con relación a esto último, en el trabajo de campo, se detectó que a pesar de los momentos difíciles que viven los jóvenes y de compartir sus miserias con sus vecinos chilenos, tratan de distanciarse de ellos a través de un discurso armado de cierto nacionalismo territorial. Por lo tanto, lo que se transmite aquí es un orgullo de pertenecer a una comunidad nacional en relación dicotómica con los que están acá, pero no nacieron acá.

Los buenos inmigrantes fueron o son los blancos, los que vinieron a trabajar, no los que vienen a quitar el trabajo. Los discursos xenofóbicos, elaborados por los sectores ilustrados, son importantes en momentos como éste, ya que descomprimen la tensión social acumulada, descargando la responsabilidad en los inmigrantes. Para los sectores dominantes es necesaria la existencia de amplios sectores de la población precarizados, o en situación de ilegalidad, lo cual les permite sostener la rentabilidad.

\section{Las manifestaciones culturales}

La identificación del grupo estigmatizado - los chilenos- dentro de la sociedad neuquina, se realiza a partir de la utilización del lenguaje, o de la celebración de fiestas, o la participación en asociaciones chilenas, o en menor medida, la mención a los apellidos paterno y materno; pero no existen "marcas físicas" que pueden identificarlos, ya que los informantes distan mucho de tener cabellos rubios y ojos celestes, sin embargo muchas veces, estas marcas se buscan; se dieron casos de respuestas en las cuales se plantea que somos todos iguales, que los chilenos tienen derechos: "no modifica para nada que vivan chilenos acá, ya que todos somos iguales, lo único que tenemos diferente es el color de la piel y el pensamiento". Pareciera ser que poseer cierta etnicidad argentina opera como un champú que blanquea la piel, por lo menos en el universo simbólico de sus miembros. Todo esto tiene que ver con el mito nacional de una Argentina igual a sociedad blanca europea, sin mezclas y sin máculas.

Si hay algo que caracteriza al Neuquén actual es su cosmopolitismo, ya que a partir de los años ' 60 fue escenario de un importante flujo de gente proveniente de distintas regiones del país, que a su vez comparten con los viejos pobladores - argentinos y chilenos- los rasgos de mestizaje. 
En el testimonio citado, si bien se aboga por la igualdad de derechos, se plantea que las diferencias existen entre nacionales y extranjeros, y son evidentes, ya que se perciben por alguna diferencia física imaginaria. Además cuando se plantea la diferencia de pensamiento, intuimos que se trata de definir dicotómicamente el asunto entre los que tienen un pensamiento racional, y los otros.

Respecto a la celebración de las fiestas patrias chilenas en el territorio -tema específico del trabajo de campo- las respuestas apuntan a mirar con un manto de sospecha -ya que no ocurre lo mismo con las celebraciones de otras comunidades como española, italiana, sirio -libanesa- , los festejos nacionales de los chilenos residentes en Neuquen, llevadas a cabo en territorio neuquino -argentino, de ahí expresiones tales como: "no estoy de acuerdo y salen a hacer disparates"; "es desubicado festejar en la Argentina, lo deberían festejar en su país"; "no las tendrían que hacer acá, porque no son argentinos"; "son una mierda, porque no se van a su país a festejar, chilenos de mierda"; "que festejen dentro de sus casas, sin molestar a nadie"; "las fiestas son muy quilomberas"; "no me gusta que festejen en mi país".

Lo del manto de sospecha, puede analizarse en referencia a algunas cuestiones específicas, por ejemplo el hecho de expresar "que vayan a su país a festejarlo" opera como una metáfora que en el fondo se puede traducir váyanse, festejen y no vuelvan más. También se puede observar algunas opiniones caritativas que estarían de acuerdo que los chilenos festejen aquí sus fiestas en el ámbito doméstico, es decir en el gueto, para evitar que se contamine el suelo patrio. Lo ruidoso de las fiestas tiene que ver con cierto estereotipo hacia el migrante trasandino de catalogarlo como de liero y borracho. La explicitación a través de una identidad chilena, es lo que genera resistencia a los nacionales, ya que verían esta manifestación como muestra de desagradecimiento hacia esta tierra.

Existen en los testimonios, respecto a este aspecto, manifestaciones de otro tipo: "veo bien el festejo de sus fiestas, ellos son patriotas nosotros no"; "admiro su forma de festejar"; se refleja aquí una mirada del festejo como símbolo de unidad, del cual los que comparten la nacionalidad argentina carecen; las fiestas patrias en Chile son festejos populares de varios días, y el "ser nacional" que se refleja en ellas, es lo deseable para nuestros entrevistados. No se descarta el hecho de que muchos de los alumnos, han participado de estas fiestas, por tener sus padres, abuelos o amigos de nacionalidad chilena; esto puede verse reflejado en testimonios de otro carácter: "es bueno que las festejen, por sus costumbres".

Hay en la sociedad neuquina un porcentaje importante de personas, que tienen en su familia a algún miembro chileno -padre, madre, abuelos, tíos-, o que comparten actividades con personas de nacionalidad chilena -en el barrio, en la escuela, en la iglesia-. En estas situaciones se dan posturas contradictorias, porque el prejuicio que se refleja en frases, o insultos, o la racionalización de ese prejuicio -"son los que nos quitan el trabajo"-, no pueden contrastarlo con un individuo en particular; al no poder sostener el prejuicio con los individuos que conocen, realizan "salvedades": "los chilenos son..., pero no todos son iguales"

En el trabajo de campo se observó que personas que son de nacionalidad chilena, o que son descendientes de chilenos, tienen en ocasiones actitudes endofóbicas. "La endofobia es el rechazo al mismo grupo original de pertenencia. Se da cuando, ya sea por escapar a situaciones de segregación o discriminación, o por un deseo de integración más rápida a la sociedad global, algunos miembros de las minorías se identifican masivamente con la cultura dominante, negando a veces a la original" (Mármora, 2000: 13). El prejuicio es internalizado por los grupos objeto de estigmatización, entonces las personas que se encuentran vinculados a este grupo, buscan separarse -"yo nací en Chile, pero me siento argentina"; "mi papá es chileno, pero hace mucho que vive acá y, ya somos argentinos"; "nosotros no participamos de las fiestas porque somos argentinos"- Y de hecho, muchos de los que utilizan un lenguaje prejuicioso, cuando se indaga respecto a su lenguaje, dicen "yo no discrimino, si mi mamá es chilena".

En el caso específico de Neuquén, resulta muy difícil para los chilenos, o hijos de chilenos, plantearse el corte de los lazos y la pertenencia a las tradiciones nacionales, porque Chile no se encuentra a miles de kilómetros de Neuquén, sino que se mantienen relaciones muy cercanas con parientes que residen al otro lado de la cordillera. Por lo tanto, la expresión de endofobia, 
no se manifiesta como un rechazo, sino más bien como un alejamiento de estas tradiciones por la incorporación de una identidad argentina. Es bastante común que el chileno naturalizado argentino al retornar a visitar parientes en Chile, se comporte como chileno. Hay un juego con las identidades.

\section{Si tuvieran decisión política...}

El otro aspecto que se trabajó con los estudiantes es el que tiene que ver con qué harían ellos, si tuvieran la responsabilidad de la toma de decisiones políticas respecto a la población chilena en el Neuquén. Las respuestas obtenidas es que en el imaginario social de los alumnos se ha incrustado la idea de que una provincia sin migrantes chilenos sería mejor para todos los nacionales. Por eso, respondieron de la siguiente manera: "los extraditaría"; "yo los echaría, no los quiero acá"; "yo los dejaría entrar como turistas, no a trabajar"; "los enviaría de vuelta a su país y que mejoren sus condiciones de vida allá"; "los aceptaría pero les limitaría los beneficios, no les daría todos los beneficios"; "los rajaría del país"; "que paguen más impuestos que los argentinos y que tengan menos prioridades".

Esto implicaría ya la discriminación hecha y derecha, es decir, existiría según sus deseos una política represiva hacia el colectivo chileno que implicaría lisa y llanamente, la expulsión de ellos. Regresarlos a su país significa que no estén acá influyendo negativamente en diversos aspectos de la vida regional, como por ejemplo en el lenguaje, en las costumbres, y por supuesto, como se planteó anteriormente como competidores desleales del complicado mercado laboral.

También algunos ejemplos, muestran a alumnos un poco "más tolerantes" con los migrantes, ya que podrían seguir viviendo acá, pero con menos beneficios y pagando más impuestos que los nacionales. Esto significa, habitantes de primera y de segunda. En la percepción de los derechos se observa que los nacionales intentan plantear con sus palabras, la etnificación del trabajo, ya que los mejores puestos deben ser para los argentinos; además de mantenerlos en un estado de desigualdad e indefensión con respecto a la sociedad nacional.

Sin embargo hay un par de opiniones, que expresan lo siguiente: "les daría como a todo el mundo trabajo"; "tienen derecho a quedarse, ya que hay argentinos que se van a otro lado para mejorar su situación"; "no haría nada en su contra, porque podemos necesitar de ellos"; si bien estas opiniones fueron minoritarias, en relación con las antes apuntadas, creemos que reflejan la opinión de un grupo de alumnos que se encuentran vinculados a miembros de la comunidad chilena familiarmente, o con creencias religiosas similares; se encuentra también presente la mirada sobre la realidad argentina, que implica que muchos de sus ciudadanos han migrado o piensan hacerlo, para mejorar sus condiciones de vida.

\section{Conclusiones}

El análisis de los datos obtenidos en esta indagación muestra el prejuicio chauvinista antichileno que tienen muchas personas pertenecientes a los sectores populares del Neuquén. Como se planteó anteriormente, los discursos prejuiciosos fueron elaborados por los sectores ilustrados, y se reproducen constantemente -incluso en la producción historiográfica- Al ser incorporados por los sectores populares no se discuten cuestiones de límites, sino que se reelaboran en función de la cotidianeidad: no se plantea la apropiación del territorio, sino la apropiación de los recursos como trabajo y vivienda, como así también el malestar que ocasiona que extranjeros festejen sus fiestas patrias en el territorio argentino.

En este contexto aparecen elementos de una utopía reaccionaria de una sociedad ideal en donde existiría trabajo, vivienda y salud, y el resguardo de la cultura nacional, posibilitado por la expulsión del chileno.

El mito de una cultura nacional homogénea, de una Argentina europea, sigue operando como cimiento de las manifestaciones de prejuicio, y se potencia en las situaciones de pobreza y marginación. 


\section{Bibliografía}

CERUTTI, A. -LVOVICH, D. (1994), Migración y prejuicio: los migrantes chilenos en el territorio del Neuquen, Argentina 1885 -1930 en Revista Cuadernos Americanos, Nueva Época, Año VIII, volumen 6, N 48, UNAM, México.

MÁRMORA, E. (1997), Los inmigrantes de los países vecinos en Klich, I. y Rapoport, M. (comp.) Discriminación y racismo en América Latina, Nuevohacer, Buenos Aires.

MÁRMORA, E. (2000), Migraciones: prejuicio y antiprejuicio en Índice Revista de Ciencias Sociales, No 20, DAIA, Buenos Aires.

THEORDESEN, G.(1978), Diccionario de Sociología, Paidós, Buenos Aires. 